\title{
A charge sob a ordem do discurso pedagógico: achados enunciativos no cenário da Educação de Jovens e Adultos
}

\author{
Raissa Regina Silva Coutinho \\ Erenildo João Carlos \\ Universidade Federal da Paraíba
}

\section{Resumo}

Este artigo, resultante de uma dissertação de Mestrado, analisa o discurso sobre o uso pedagógico da charge na Educação de Jovens e Adultos (EJA). A o considerar esse gênero textual como um acontecimento discursivo, a pesquisa realiza uma análise descritiva das singularidades dos discursos, materializados em produções acadêmicas, que anunciam e recorrem à charge como estratégia relacionada à formação dos sujeitos da EJA. Para tanto, utiliza-se como ferramenta a Análise Arqueológica do Discurso de Michel Foucault (2012). Em suma, concluiu-se que, nesse cenário, o professor aparece em uma posição de sujeito mediador, e o aluno da EJA, como um sujeito construtor e autônomo no trabalho pedagógico. $\bigcirc$ uso pedagógico da charge, como modalidade de leitura, promove uma relação triádica, em que se inserem o sujeito, o texto e a realidade, o que possibilita um processo de reflexão, problematização, levantamento de conhecimentos prévios, compreensão, interpretação, criticidade

Palavras-chave: Discurso. Charge. Educação de Jovens e Adultos.

\section{The cartoon under the pedagogical discourse order: enunciatory findings on Youth and Adults Education}

\section{Abstract}

This article, resulting from a Master's thesis, investigates the discourse on the pedagogical use of the cartoon in the Youth and Adults Education (YAE). To consider this textual genre as a discursive event, the research carries out a descriptive analysis of the singularities of discourses, materialized in books and academic productions, that announce and use the cartoon as a strategy related to the training of the subjects of the YAE. Therefore, the Archaeological Analysis of the Speech of Michel Foucault (2012) is used as a tool. In sum, it was identified that in this scenario the teacher appears in a position of mediating subject and the student of the YAE as a constructor and autonomous subject in the pedagogical work. The pedagogical use of the cartoon, as a reading modality, promotes a triadic relationship, in which the subject, the text and the reality are inserted, which allows a process of reflection, problematization, previous knowledge, understanding, interpretation, criticality and dialogue.

Keywords: Discourse. Cartoon. Youth and Adults Education. 


\section{La viñeta bajo el orden del discurso pedagógico: hallazgos enunciativos en el escenario de Educación de Jóvenes y Adultos}

\section{Resumen}

El presente artículo, resultante de una disertación de Maestría, analiza el discurso pedagógico de la viñeta en Educación de Jóvenes y Adultos (EJA). Al considerar este género textual como un acontecimiento discursivo, la investigación realiza un análisis descriptivo de las singularidades de los discursos, materializados en libros y en producciones académicas, que anuncian y recurren a la viñeta como una estrategia relacionada a la formación de los sujetos de la EJA. Para ello, se utiliza como herramienta el Análisis Arqueológica del Discurso de Michel Foucault (2012). En resumen, se concluyó que, en ese escenario, el profesor aparece en una posición de sujeto mediador y el alumno de EJA como un sujeto constructor y autónomo en el trabajo pedagógico. El uso pedagógico de la viñeta, como modalidad de lectura, promueve una relación triádica, en la que se inserta el sujeto, el texto y la realidad, lo que posibilita un proceso de reflexión, problematización, levantamiento de conocimientos previos, comprensión, interpretación, criticidad y el diálogo.

Palabras clave: Discurso. Viñeta. Educación de Jóvenes y Adultos.

\section{Introdução}

As linguagens visuais, em especial, as charges, cada vez mais, fazem parte do cotidiano das pessoas. E alguma das razões são a maior abrangência e a relação de dependência dos sujeitos com as tecnologias de comunicação e informação, bem como a rapidez e o volume com que essas múltiplas linguagens circulam no mundo nesses artefatos.

Na área da educação, propriamente dita, a charge se faz presente em livros didáticos e em instrumentos avaliativos, como ferramenta pedagógica no processo de ensino, entre outras possibilidades. Seu conteúdo de cunho político, ideológico e social contribui para que determinadas visões de mundo entrem em cena e provoquem o sujeito, com quem estabelece uma relação de aproximação, a pensar, a criticar, a expressar uma opinião e, até mesmo, a rir.

Refletir sobre essa presença é imprescindível nesse processo de abstração e de explicitação dos aspectos que apontam a relevância da pesquisa de modo geral. Entretanto, não é o foco deste trabalho abordar as imagens em sua existência empírica ou em materiais didático-pedagógicos, porque o foco é analisar o discurso acerca da charge em seu uso pedagógico. Em 
outras palavras, o conjunto de coisas escritas, materializadas em textos acadêmicos, que consistem em apresentar como tal artefato, é utilizado no campo educacional.

Trata-se de um processo de análise que se empreende ao identificar e organizar os achados discursivos acerca de suas especificidades como forma de representação particular, de tal forma que se apresentem as correlações entre a charge e o campo da educação, em especial, no tocante à formação do sujeito da EJA, na perspectiva de entender as particularidades, as possibilidades e as contribuições de seu uso pedagógico. Diante disso, o presente artigo tem como objeto de discussão o discurso sobre o uso pedagógico da charge na EJA.

A pesquisa, de cunho qualitativo, foi empreendida por meio da Análise Arqueológica do Discurso (AAD) proposta por Michel Foucault (2012), tendo como fonte os estudos bibliográficos acerca do assunto. $\bigcirc$ conjunto de coisas escritas foi analisado e descrito em seu nível de existência para se entender o objeto da pesquisa. Os procedimentos metodológicos básicos da pesquisa com referência na AAD são: mapeamento, escavações e análise descritiva' .

Por meio das escavações efetivadas na ordem do discurso pedagógico, nos documentos que trazem uma dimensão do objeto pesquisado, viabilizou-se uma organização do conjunto de coisas escritas para que fosse possível identificar os aspectos que são necessários para que se possa entender as questões elaboradas a priori. As descrições enfatizam as regularidades postas no discurso, o que delimita a estrutura organizativa deste texto. Inicialmente, apresentam-se as particularidades da charge que estão postas no discurso. Em seguida, sob o signo sujeitos, aponta-se quem compõe o processo de uso pedagógico da charge. Por fim, apresentam-se as especificidades do uso pedagógico desse gênero e se aponta como esse signo se explicita e se desdobra em regras, correlações e estratégias no terreno discursivo em que se concebe a charge.

\section{A charge}

Entre os inúmeros exemplos de artefatos da cultura visual, a charge aparece de modo particular e suscita um olhar sobre a realidade de modo crítico e cômico. Esse gênero textual aborda a realidade e chama a atenção dos sujeitos para determinados acontecimentos da sociedade. Apresenta um 
forte caráter político, e uma de suas principais funções sociais é de denunciar. Rompeu as páginas dos jornais e passou a ocupar, também, as homepages da internet. Não por caso, vem sendo objeto de pesquisa de variadas áreas do conhecimento, como Filosofia, História, Psicologia, Comunicação Social, Letras e Pedagogia, o que configura seu caráter interdisciplinar.

A charge é uma representação gráfica no terreno epistemológico, cuja abordagem consiste em apresentar acontecimentos da atualidade, permeabilizada pelo entrecruzamento de discursos em uma perspectiva crítica e humorística. Para tanto, por meio do desenho e do texto escrito, constrói determinado cenário e seus personagens para evidenciar um fato ou acontecimento que repercutiu na sociedade.

Mouco e Gregório definem a charge como uma

[...] crítica humorística de um fato ou acontecimento específico. É a reprodução gráfica de uma notícia já conhecida do público, segundo a percepção do desenhista. Apresenta-se tanto através de imagens quanto combinando imagem e texto. A charge absorve a caricatura em seu ambiente ilustrativo (MOUCO; GREGÓRIO, 2007, p. 5)

É importante fazer a distinção entre caricatura, cartum, tirinha e charge, como um dos componentes das regras empreendidas para explicitar a charge de modo singular. Por meio dessa estratégia, pode-se explicar a charge como uma representação particular que estabelece uma relação com a realidade retratada, diferentemente de outras formas humorísticas.

Nesse cenário, a caricatura, regularmente, é associada através do signo "exagero". Silva (2008) concebe a charge como um tipo de humor gráfico, por meio do qual se recorre ao exagero como um recurso cômico para realçar as características físicas marcantes do indivíduo, com transgressões estéticas que induzem ao riso. A caricatura também é um dos elementos que constituem a charge, e o cartum é associado a um signo atemporal e universal, que não se situa em determinado contexto histórico e social. Silva (2008, p. 80) assevera que o cartum "[...] não faz referência a nenhuma personalidade ou fato do noticiário". Logo, a charge se diferencia tanto da caricatura, por abordar um acontecimento, e não, apenas, o indivíduo, quanto do cartum, por estar vinculada a um recorte temporal e a contexto social. 
Agostinho (1993), a partir do domínio de conhecimento da Arte, compreende a charge como arte gráfica e diz que, diferentemente do quadrinho e do cinema, a narrativa da charge acontece, invariavelmente, em um só quadro e raramente o artista recorre à divisão do espaço em duas ou mais partes para realizar o processo de representação. Por meio da diferenciação, como componente da regra discursiva, a afirmação aponta o modo particular da charge de buscar resumir-se em um só quadro, o que a distância de ser confundida com os quadrinhos ou as tirinhas.

Os elementos constitutivos da charge que aparecem no discurso são: linha, cenário (fundo), espaço, plano, luz, sombra, movimento, ícones, símbolos, intertextualidade, paródia, metáfora, onomatopeia, sátira, humor, ironia e caricatura. Através dessa articulação entre a linguagem verbal e a visual e as estratégias de produção da comicidade, a charge desperta o riso e a comicidade. Assim constituída, expressa-se de modo particular, objetivo, simultâneo, crítico e humorístico.

Na ordem ideopolítica do discurso, Maggioni (201 1, p. 35) suscita que "[...] a função social da charge vai além da distração, pretendendo ela alertar, denunciar, coibir e promover a reflexão". Há que se ressaltar que a 36 função da charge, como humor gráfico, não se restringe ao ato de fazer rir ou de distrair, pois contempla um conjunto de outras funções que direcionam sua intencionalidade, com o fim de denunciar e alertar o sujeito sobre determinado acontecimento e provocar reflexões críticas a respeito de certas visões de mundo.

Pires (2010, p. 61), partindo de uma análise das charges de Ângelo Agostini², afirma que, ao abordar a política, a charge ressalta "[...] o descaso dos políticos para com as demandas populares". É preciso salientar que a crítica suscitada na charge apresenta um caráter político, cuja característica essencial, conforme Silva (2008, p. 2), é "a crítica desvelada ao poder". $\bigcirc$ caráter político é um aspecto marcante e peculiar da charge, já que ressalta seu comprometimento em retratar as problemáticas sociais e as relações de poder.

discurso humorístico traz uma visão crítica de assuntos do dia a dia e suas estratégias para surpreender o sujeito e provocar-the o riso. Melo (2004, p. 73) assevera que é preciso haver uma distinção no humor, porque nem todo humor "[...] pretende atingir o governo, questionar a sociedade ou 
atingir os poderosos". A autora refere que existem dois tipos de humor: o crítico e o banal. E embora a charge seja considerada como um humor crítico e esteja ligada à arte-de-fazer-rir, seu compromisso é muito mais com a verdade das coisas do que com o riso.

Albuquerque e Oliveira (2008) suscitam o caráter não oficial da charge, como também seu caráter revolucionário e popular, uma vez que aborda as relações antagônicas entre aqueles que detêm o poder e as camadas populares e visa questionar o poder interruptamente. Apresenta-se que o papel do humor na charge é de questionar o poder como uma constante, por isso é sobremaneira revolucionária. Quando Chaplin fazia de bobo um guarda de rua, em seus filmes, sabia que ridicularizar o poder descontrai o ser humano e o faz rir. Ver o sujeito que se posiciona em um lugar de poder, ocupa um lugar que o ridiculariza e o critica possibilita um riso como unidade de uma diversidade de sujeitos e seus anseios, que se encontram alheios a esse poder. Logo, o humor se contrapõe às regras sociais, questionando-as, ao mesmo tempo que descontrai a sociedade diante de suas angústias. $O$ enunciado "ridicularizar o poder" suscita a relação antagônica entre a elite e o povo. Além disso, a charge é considerada "altamente revolucionária" por explicitar essa intencionalidade de questionar o poder e evidenciá-lo em suas contradições.

A seguir, analisa-se como os sujeitos aparecem no enredo discursivo do uso pedagógico da charge na EJA, mais especificamente, as características comuns que os identificam como alunos e professores dessa modalidade e as aproximações e os desafios que configuram nesse contexto pedagógico.

\section{Os sujeitos}

Nos escritos analisados, aparecem séries de signos que se articulam e difundem vários aspectos que corroboram para especificar os sujeitos que constituem e dinamizam esse cenário. Para compreender o uso pedagógico da charge na EJA, é imprescindível compreender quem são esses sujeitos, suas características, suas relações com o cenário social e escolar, suas dificuldades e necessidades.

Para tanto, nos escritos analisados, aparece um conjunto de enunciados que caracterizam os alunos da EJA, constituindo um perfil específico, assim 
como no caso do professor, a respeito do qual aparecem enunciados que caracterizam sua posição de sujeito no processo pedagógico. Assim, foram descritos os enunciados acerca da posição de sujeito dos alunos da EJA e do professor, como forma de especificar suas condições de existência e funções em nível discursivo.

\section{Sob o signo "alunos da EJA"}

Nery (201 1, p. 27) apresenta vários enunciados que especificam, de modo regular, os alunos da EJA. $\bigcirc$ signo trabalho delimita a função enunciativa. Assim, tais enunciados apresentam que: "[...] a grande maioria dos alunos já está inserida no mercado de trabalho, quer seja com carteira de trabalho assinada ou em subempregos"; cumprem "uma carga de trabalho extensa e cansativa [...]; precisam deixar seus filhos sozinhos para poderem estudar $[. . .]^{\prime \prime}$; as mulheres têm a "[...] necessidade de trabalhar fora para ajudar no sustento da casa"; elas têm que "[...] cuidar dos afazeres domésticos [...]". Percebe-se, também, que a posição de sujeito da mulher constitui uma especificidade e um posicionamento diferenciado, e a ela são atribuídos determinados papéis ou funções, como a de trabalhar para complementar a renda familiar e desempenhar os afazeres domésticos.

A relação do aluno com o trabalho, em suas extensas horas de serviço e em seu cansaço, interfere em sua relação com a escola. As séries de signos seguintes confirmam essa assertiva: "[....] são alunos que não têm muito tempo para dedicarem aos estudos [...] na maioria das vezes, estudam somente quando estão na escola" (NERY, 201 1, p. 27). Tais aspectos aparecem como algumas das dificuldades apresentadas pelos sujeitos da EJA.

Outro aspecto que caracteriza a relação dos alunos da EJA com a escola é a reprovação, pois alguns deles outrora tiveram acesso ao processo de escolarização, mas não conseguiram continuar, a EJA é uma oportunidade de recomeçar os estudos: "[...] alguns foram reprovados [...]" e "[...] voltaram alguns anos depois para a EJA" (NERY, 2011 , p. 27).

Nas relações em que o aluno da EJA se insere, o discurso aponta que "[...] são alunos que têm um grande interesse em estudar, mas que se sentem rejeitados, excluídos e com muitas dificuldades de aprendizagem" (NERY, 2011 , p. 46). Essas séries de signos apontam como os alunos se sentem no 
contexto educacional. A rejeição, a exclusão e as dificuldades de aprendizagem permeabilizam o processo pedagógico com os jovens e os adultos, caracterizando as relações estabelecidas e o posicionamento desses sujeitos.

Sobre as dificuldades que os jovens e os adultos apresentam ao longo do processo pedagógico, Nery (201 1, p. 17) assevera que "[...] estão relacionadas à leitura e à escrita". Assim, o processo de compreensão de textos é apontado como um sério problema na formação dos alunos da EJA, como demonstrado neste recorte: "Diante da nossa vivência com a Educação de Jovens e Adultos, que os alunos, desde as séries iniciais até o Ensino Médio, apresentam sérios problemas na compreensão de textos por mais simples que esses possam ser" (NERY, 201 1, p. 17). Por meio do signo dificuldade, aponta-se para as habilidades de leitura e de escrita, canalizando-se para o tocante à capacidade de compreender textos. Tal capacidade confere se a leitura e a escrita se desenvolvem de maneira eficiente e qualitativa. A partir do que está posto, identifica-se, em relação à leitura e à escrita, a compreensão de texto associada a dificuldades de aprendizagem, o que elucida a relação dos sujeitos com os textos utilizados e as atividades realizadas com o professor.

Em face das referidas dificuldades dos alunos, as articulações presentes no discurso apresentam os aspectos necessários para potencializar o seu processo pedagógico: "[...] faz-se necessária a utilização de propostas pedagógicas que auxiliem o processo de ensino-aprendizagem, principalmente, no que concerne à produção de leitura" (NERY, 2011 , p. 17). Além disso, tais propostas pedagógicas devem utilizar gêneros de linguagem por meio dos quais os alunos se posicionem criticamente e não compreendam somente as coisas ditas, mas também as condições em que o texto foi produzido.

Em relação ao que foi dito sobre os alunos da EJA e as dificuldades acerca do processo de leitura e de escrita no tocante à compreensão textual, um aspecto é bastante pertinente para esta pesquisa, que aparece na seguinte afirmativa: "[...] um público de faixa etária diferente do Ensino Regular, na maioria das vezes, apresenta uma vivência maior com as charges e com as situações sociais representadas nesse gênero" (NERY, 2011 , p. 19). $\bigcirc$ discurso aponta, como particularidade, a relação de aproximação dos alunos da EJA com as charges, que difere da relação do aluno do Ensino Regular. $O$ aspecto que propicia essa aproximação é estabelecido pela vivência desses sujeitos. Assim, de modo geral, traz para sala de aula uma relação de não indiferença a determinados artefatos como a charge e os fatos representados. 
Essa característica configura um aspecto que facilita a utilização da charge no processo pedagógico com os sujeitos jovens e adultos.

Analisar as especificidades dos jovens e dos adultos, atentando para suas necessidades e potencialidades, contribui para que se otimizem o pensar e o fazer pedagógico perante as propostas que se pretendem realizar com os educandos. Compreender como os sujeitos se relacionam com a charge, em suas aproximações e distanciamentos, viabiliza as possibilidades e as contribuições desse objeto em seu uso pedagógico.

Em linhas gerais, a EJA é uma modalidade desafiadora para os professores. Os alunos são descritos como um público bem heterogêneo, com expectativas, desejos e níveis de aprendizagem diferenciados (NERY, 2011 ). Como um aspecto regular e que demarca essa modalidade, a heterogeneidade envolve um público que, apesar dos aspectos comuns como os que se referem ao âmbito do trabalho, apresentam particularidades que se diferenciam de um sujeito para outro.

No campo pedagógico, os alunos são reconhecidos como sujeitos autônomos e construtores do processo de aprendizagem (DAGOSTIM, 2009). Reconhecer essa posição de sujeito é uma forma de nortear o conjunto de coisas escritas que elucidam as relações intersubjetivas no cenário pedagógico, principalmente no que tange à relação entre o professor e os alunos. Assim, o trabalho pedagógico apresentado no discurso sobre o uso pedagógico da charge apresenta determinada compreensão de sujeito, que se articula e se desdobra em um modo de usar ou de fazer no processo de ensino e aprendizagem.

\section{O professor sob o signo 'mediador'}

Entre os sujeitos da EJA, também há séries de signos que regularizam a figura do professor. Para tanto, os escritos em Dagostim (2009, p. 8) apresentam que "[...] o professor torna-se um mediador" e o conjunto de coisas escritas postas em Nery (201 1, p. 116 e 107) afirma que "[...] o professor é o mediador do trabalho realizado na sala de aula". Assim, no discurso sobre o uso pedagógico da charge, o professor "[...] é o responsável pela mediação do processo de ensino-aprendizagem". Dessa forma, é claramente compreendido que o professor tem a função de mediar o processo de compreensão da charge no trabalho pedagógico com os alunos. 
A eficiência da formação dos alunos depende, além de outros aspectos, de como essa mediação prossegue, porquanto "[...] a mediação do professor é decisiva para que as atividades planejadas atinjam os objetivos pretendidos" (NERY, 2011 , p. 111 1). Logo, a mediação pressupõe o planejamento, e ambos aparecem em uma relação de interdependência, cujos objetivos pretendidos devem estar explícitos, norteando os caminhos a serem percorridos nas atividades, com o intuito de alcançar as expectativas geradas ao se usar a charge pedagogicamente com os educandos jovens e adultos.

Apresenta-se "[...] uma ação pedagógica não separada de uma visão de mundo e de uma posição política que definem o posicionamento do educador no jogo das relações sociais" (SOUZA, 2000, p. 60). Não por acaso, o professor se posiciona de uma maneira, e não, de outra. $\bigcirc$ discurso interdita e torna ausente uma posição neutra do professor no cenário pedagógico, cujo posicionamento é orientado por uma série de regras que refletem certa visão de mundo e posição política.

conjunto de coisas escritas aponta várias séries de signo que qualificam os sujeitos nesse cenário. Embora o professor seja imprescindível em todo o processo pedagógico, sua posição como mediador não define os resultados da aprendizagem isoladamente. Portanto, o aluno aparece como corresponsável pelos resultados, posiciona-se no centro do processo e é reconhecido como construtor do próprio aprender. Essa assertiva se confirma nos seguintes escritos:

Antes a professora, nesse caso, eu, era o centro do processo, quem definia cada atividade e cada proposta; a partir do trabalho com charges, os alunos tornaram-se construtores e, dessa forma, passei a ser a mediadora do processo de aprendizagem, e o aluno, além de centro, corresponsável pelos resultados de aprendizagem. Até mesmo a relação com os alunos foi afetada, de modo positivo, por meio das atividades: estar nos grupos, discutir junto, perceber o quão responsáveis se tornam ao demonstrar liderança, tudo isso também faz parte do processo educacional (DAGOSTIM, 2009, p. 95).

Assim, os sujeitos se posicionam no discurso, pois a ordem do discurso pedagógico, com seus desdobramentos, possibilita determinadas posições e relações. Nesse contexto, o discurso confere ao professor a posição de mediador do processo pedagógico, e os alunos, como construtores, ocupam o lugar 
A charge sob a ordem do discurso pedagógico: achados enunciativos no cenário da Educação de Jovens e Adultos

central desse processo. Tais posicionamentos aparecem como um dos componentes das regras do discurso.

\section{O uso pedagógico}

Os escritos postos em Souza (2000) estabelecem uma compreensão acerca da charge e apresentam uma correlação com os escritos de Certeau (1994), que, por sua vez, traz o signo 'uso' ou 'modalidade de uso', com o intuito de abordar o uso que o leitor-pesquisador faz da leitura das charges, que remete às maneiras de fazer. Desse modo, compreender o uso da charge no âmbito pedagógico apresenta uma articulação com várias séries de signos que se conectam às maneiras de fazer em suas múltiplas formas e aspectos.

$\bigcirc$ discurso sob a ordem pedagógica apresenta signos que, em suas relações, apresentam o discurso sobre o uso pedagógico da charge de modo específico. Portanto, além dos signos que remetem aos sujeitos, há os que se referem, especificamente, ao uso pedagógico em suas "maneiras de fazer". A charge é concebida como uma "modalidade de leitura" (SOUZA, 2000). Assim, tem-se a leitura como uma modalidade de uso pedagógico da charge,

42 enfatizado ao longo do conjunto de coisas escritas, em seus variados desdobramentos, um esclarecimento acerca de como esse processo de leitura se apresenta no processo de ensino e aprendizagem de jovens e adultos. Ao entender essa conexão entre os signos charge e leitura, o discurso apresenta também os signos compreensão e interpretação, em uma relação de interdependência, articulando-se de modo complementar.

$\bigcirc$ discurso assinala que é preciso "[...] perceber que não há uma única possibilidade de leitura, uma vez que os sentidos não são fixos" (NERY, 2011 , p. 1 16), assim como "[...] os sentidos não são dados de forma direta e não há um sentido único" (DAGOSTIM, 2009, p. 24). Entretanto, afirma-se que "[...] há muitas formas possíveis de ler, mas temos que ficar cientes de que não são infinitas, pois estamos inseridos num contexto sócio-histórico que interdita e possibilita nossos dizeres" (NERY, 2011 , p. 55). $\bigcirc$ processo de leitura é entendido como um cenário de possibilidades múltiplas, o que contrapõe à ideia de leitura numa perspectiva unívoca. Por outro lado, essas possibilidades são consideradas finitas e condicionadas, uma vez que é preciso considerar as condições de produção da charge, dependendo do contexto em que isso ocorre. Portanto, os sentidos não são fixos e únicos, o que significa que a 
interpretação e a compreensão acontecem de modo amplo, dinâmico, contextualizado e articulado.

A charge, como uma modalidade de leitura, é trabalhada pedagogicamente de modo que o aluno tente ir além do que está meramente explícito e compreender que não há uma única possibilidade de leitura. Assim, ele é conduzido, por meio da mediação, a "[...] refletir sobre o que lê, a penetrar a profundidade do texto, a utilizar seu conhecimento de mundo e, principalmente, a tirar suas próprias conclusões para a construção do conhecimento" (NERY, 2011 , p. 98). Portanto, não basta ao aluno ler, mas também refletir sobre o que leu, porque é construtor do processo de leitura, e não, mero reprodutor. Percebe-se o quão é amplo e significativo o processo de leitura considerado no discurso, visto que tanto contempla a reflexão quanto a valorização do conhecimento de mundo do aluno e as conclusões a que chegou ao longo do processo.

Nesse horizonte discursivo, os signos se articulam de modo a constituir como o processo de leitura da charge se apresenta e se desenvolve. Alguns desses signos são: leitura, compreensão, interpretação, conhecimentos prévios, procedimentos de leitura, criticidade, possibilidades e contribuições. A seguir, apresentam-se algumas especificidades que esclarecem o uso da charge como modalidade de leitura, em particular, no âmbito da EJA, sistematizado com base nas regularidades existentes no conjunto de coisas escritas.

\section{A tríade leitor, texto e realidade}

O uso pedagógico da charge pressupõe "[...] a capacidade de usar o olhar como possibilidade de leitura do mundo" (SOUZA, 2000, p. 66). A charge pressupõe e desperta a capacidade do uso do olhar, uma vez que contém elementos verbais e visuais e viabiliza habilidades e regras específicas para cada tipo de linguagem. A existência das séries de signo "leitura do mundo", através do uso da charge, aponta que essa forma de representação estabelece uma conexão com o mundo e concebe a realidade em determinada perspectiva, em que, com seu olhar, o sujeito viabiliza um modo de leitura específico. Desse modo, a charge aparece entre o olhar e o mundo e possibilita uma aproximação entre esses dois eixos.

Essa compreensão de que a leitura da charge traz para o sujeito uma conexão com o mundo, representando-o e reconstruindo-o, também aparece 
em Souza (2000, p. 61), que afirma que "[...] uma relação entre as imagens fixadas em sua integração com o mundo, possibilita abstrair do universo visual, uma vez representado, todo um conteúdo da realidade selecionada reconstruída através de informações múltiplas".

Sob o ponto vista de Nery (201 1, p. 37), o discurso, em sua materialidade, o texto chárgico, passa a ser entendido como uma "[...] construção social, que posiciona os sujeitos como participantes dos processos de construção de significados". Como pressuposto do uso pedagógico da charge, a "[...] leitura como prática social, abarcando a dinamicidade leitor-texto-realidade" (SOUZA, 200, p. 57). O discurso aponta a dimensão social da leitura, pois tal prática é constituída coletivamente e viabiliza formas determinadas de conceber a realidade. Além disso, apresenta-se como um dos componentes da regra do discurso a relação triádica, composta pelo leitor, pelo texto e pela realidade, considerada como uma relação dinâmica, até porque esses três componentes apresentam suas variáveis e particularidades.

Tendo como base a identificação dessa relação triádica no trabalho pedagógico, os sujeitos precisam "[...] relacionar o que é lido com o contexto em que se encontram inseridos" (NERY, 2011 , p. 113). No discurso, é ressal-

44 tada a necessidade de articular o texto com o contexto, trazendo a realidade dos sujeitos para compor o processo de significação da leitura. Dessa forma, a realidade do aluno e a realidade representada na charge são postas em relação sob o signo da leitura. Segundo Souza (201 1, p. 257), " [...] o contexto sócio-histórico-cultural dos alunos leitores deve ser considerado diante do processo educacional". Nesse contexto, considerar o contexto do leitor é um requisito para o decorrer do processo. Logo, a realidade do aluno e a realidade representada no texto chárgico são mediatizadas pela leitura.

Diante do exposto, destaca-se que "[...] o processo de produção de sentido é o fruto da ação interativa de um sujeito social, histórica e culturalmente situado" (SOUZA, 201 1 , p. 250). Dessa forma, o sujeito não aparece neutro, mas situado no âmbito social, histórico e cultural, sendo o seu processo de leitura articulado, em sua construção de sentidos, com o contexto no qual está inserido. $O$ aluno como construtor não é considerado um sujeito passivo, uma vez que se aponta um sujeito de modo interativo, em que sua inserção contextual interfere em sua produção de sentido. 
O discurso aponta que a atividade de leitura deve enfatizar que os sujeitos devem "[...] assumir sua posição enquanto sujeitos individuais, mas, ao mesmo tempo, pertencentes a determinadas instituições que os tornam sociais" (NERY, 2011 , p. 56). Portanto, a leitura deve viabilizar uma conexão com o cenário social dos sujeitos, uma vez que é nessa articulação que surgem conhecimentos de mundo que contribuem para o processo de construção da leitura dos alunos.

A leitura aparece como uma mera interpretação descontextualizada e restritiva, haja vista uma abordagem acerca do texto que se apresenta em determinado cenário social. Nery (201 1, p. 48) afirma que "[...] ler não é apenas interpretar, mas compreender e refletir sobre o que se lê a partir de uma posição social". O ato de ler deve remeter os sujeitos a um processo amplo de interpretação, compreensão e de reflexão sobre o que foi lido na situação social que fez emergir o texto chárgico.

A abordagem acerca das charges, como registros sociais e históricos, no âmbito pedagógico, busca caminhos que viabilizam "[...] torná-los campo fértil para leitura e interpretação de um determinado momento histórico circunscrito nos traçados e verbetes" (SOUZA, 2000, p. 28). E, como a charge é de natureza temporal, o processo de leitura conduz o leitor a se situar historicamente.

Ademais, para se compreender a charge, é preciso "[...] buscar informações contextuais, isto é, no tempo e no espaço em que ocorreu" (SOUZA, 2004, p. 239). A identificação das informações do cenário sócio-histórico representado na charge aparece como pressuposto para um processo de compreensão. Lessa $(2013$, p. 10) reforça a necessidade de buscar informações contextuais, ao afirmar que "[...] o público leitor deve ter informações suficientes para efetuar o destroncamento semântico determinado entre as palavras e imagens para poder obter uma compreensão ativa desse gênero". Por último, os escritos de Silva $(2004$, p. 14) sugerem que, para "[...] ler e entender a charge, é necessário lançar mão de informações contextuais [...]", ou seja, as informações contextuais são um pré-requisito para que se compreenda a charge na ordem do discurso pedagógico.

É preciso, ainda, "[...] remeter às condições de produção e relacionar ao contexto sócio-histórico e ideológico" (NERY, 2011, p. 18). Trabalhar a charge pedagogicamente, como modalidade de leitura, diverge de formas 
de abordagens passivas, neutras e descontextualizadas, pois o discurso traz que é preciso compreender as condições em que a charge é produzida e seu contexto sócio-histórico e ideológico. Portanto, a charge, como modalidade de leitura, requer uma constante relação com o contexto.

Em suma, a partir de uma relação triádica, o leitor lê texto chárgico, tomando como base sua interação com o contexto em que se insere e as informações contextuais acerca da realidade representada, desvelando um determinado cenário sócio-histórico.

\section{Alguns procedimentos para a leitura da charge}

As séries de signos, em suas articulações, apontam alguns procedimentos que podem ser empregados no processo de leitura da charge. Esses procedimentos devem ser empregados no processo de compreensão e de interpretação desse gênero textual.

Primeiramente, deve-se observar as particularidades da charge. Os procedimentos apresentados são as projeções de tiras, histórias em quadrinhos, cartum e charges, e, por meio da estratégia da diferenciação, ressaltar as particularidades da charge. De acordo com Nery (201 1, p. 40), "[...] em transparências, tiras, história em quadrinhos, cartum e charges. Realizamos uma leitura coletiva dos gêneros, para que os alunos observassem as particularidades de cada um". Portanto, os alunos devem ser conduzidos a encontrar as semelhanças e as diferenças nessas variadas formas de representação que se aproximam da charge, por se tratar de artefatos visuais no âmbito do desenho e do humor.

Outro procedimento consiste em identificar a relação entre a linguagem verbal e a não verbal. A articulação entre esses dois tipos de linguagem é um aspecto imprescindível a ser enfatizado no processo de leitura. Assim, sobre o processo de leitura da charge, aparecem os seguintes escritos: "[...] identificar a relação entre a imagem e a escrita" (SILVA, 2004, p. 14); "[...] pedimos para que atentassem para a linguagem verbal e não-verbal empregadas nas charges" (NERY, 2011 , p. 41). Conforme já foi afirmado, a charge apresenta uma hibridez quanto à linguagem verbal e à não verbal em sua composição. Nesse horizonte, o discurso denota que é necessário identificar essa relação como um dos procedimentos a serem empreendidos no processo de leitura da 
charge, uma vez que ambos os tipos de linguagem se complementam na construção de significados e apresentam suas particularidades.

É preciso, ainda, localizar informações existentes na charge por meio de uma leitura atenta aos aspectos emitidos pela articulação entre a linguagem verbal e a não verbal. Para conduzir os alunos a encontrarem informações, é necessário partir das seguintes questões: $\bigcirc$ quê? Quem? Onde? Como? Quando? Qual? Para quê? (SOUZA, 201 1). Eles devem, ainda, localizar as informações implícitas, porque, embora nem todas as informações estejam tão visíveis na charge, podem ser deduzidas nas marcas deixadas pelo texto chárgico. Assim, com essas inferências, podem efetivar o processo de interpretação.

De acordo com Macêdo e Souza (2007, p. 1), o processo de compreensão e interpretação da charge deve ocorrer "[...] com base nas inferências que o aluno possa realizar de acordo com seu conhecimento de mundo [...]", a partir do qual ele constrói uma série de inferências. Para isso, ele deve atentar para as condições em que foi produzida e os fatores que influenciaram sua constituição (NERY, 201 1), pois compreender a charge depende dessas condições e de fatores que contribuem para constituíla, para que o leitor possa fazer suas inferências em coerência com esses pressupostos.

Tendo como base os escritos presentes em Souza (201 1, p. 256), percebe-se que o "[...] conhecimento prévio relacionado às condições de produção da charge por parte do leitor [...]" é uma das regularidades do discurso sobre o uso pedagógico da charge. Assim, no trabalho pedagógico com a charge, existe uma articulação entre o conhecimento prévio e as condições em que ela foi produzida como uma estratégia no processo de leitura.

Para "[...] os alunos desenvolverem as atividades, foi necessária a leitura de outros textos da esfera jornalística (DAGOSTIM, 2009, p. 98), a fim de fazer associações e registrar as conclusões por meio da escrita ou da oralidade". A autora acrescenta que, diante das informações implícitas e das inferências, poderá ser preciso correlacionar a charge a outros textos, em especial, aos do gênero jornalístico, para potencializar a leitura e tecer considerações a partir do que foi lido. Portanto, no uso pedagógico da charge como modalidade de leitura, é necessário inferir informações implícitas e considerar suas condições de produção e fazer correlações com outros textos que se relacionem com a realidade representada no texto chárgico. 
Identificar o tema é mais um procedimento a ser considerado nesse contexto. Por meio de questionamentos, o discurso atenta para este aspecto: que tema é tratado na charge? (NERY, 2011 ) o texto trata do quê? (SOUZA, 20111 . A resposta para essas questões é essencial para a leitura, uma vez que o tema é o eixo central do texto.

Convém enfatizar que, nem sempre, o tema vem explicitado, mas deve ser percebido pelo leitor através de sua interpretação. $\bigcirc$ conjunto de coisas escritas apresenta que identificar o tema é imprescindível na leitura da charge. Souza (2011) explica que

o tema é o eixo sobre o qual o texto se estrutura. Em muitos textos, o tema não vem explicitamente marcado, mas deve ser percebido pelo leitor, quando ele identifica a função dos recursos utilizados, como o uso de figuras de linguagem, de exemplos, de determinada organização argumentativa, entre outros. Espera-se verificar a capacidade do aluno de construir o tema do texto a partir da interpretação que faz dos recursos utilizados pelo autor (SOUZA, 2011, p. 2521.

Assim, o tema é o eixo estruturador do texto, e só pode ser identificado com a articulação dos elementos utilizados para constituir a charge em determinada organização argumentativa acerca de uma dada realidade representada. É preciso, ainda, perceber os efeitos de ironia e de humor que permeiam esse gênero textual e que são empregados como estratégias para constituir seu sentido. De acordo com Souza (201 1, p. 253), "[...] o humor e a ironia costumam ser comuns em vários gêneros de texto, mas nem sempre são facilmente compreendidos pelo leitor, pois, muitas vezes, exigem o conhecimento de situações que não são mencionadas no texto". Tais elementos se articulam, em muitas circunstâncias, com aspectos ou informações implícitas no texto. Os efeitos de ironia e de humor são utilizados estrategicamente pela charge para enfatizar determinada situação de modo específico e devem ser percebidas para provocar efeitos de sentido no leitor.

Por fim, deve-se identificar a crítica como procedimento utilizado na leitura da charge. Para isso, o mediador usa questões para despertar a atenção dos alunos para a crítica empreendida no texto chárgico, conforme destacado nos seguintes recortes: "Qual é a crítica que o autor do texto visual pretende repassar?" (SOUZA, 2004, p. 262); "Qual a crítica que está sendo feita nas 
charges? Vocês concordam com a crítica que está sendo feita?" (NERY, 2011 , p. 57). Além de o mediador incentivar a busca pela identificação da crítica existente na charge por meio das perguntas apresentadas, o sujeito é estimulado a participar desse processo, apresentando seu posicionamento e/ou sua opinião sobre a crítica.

Há que se ressaltar, contudo, que o discurso acerca do uso pedagógico da charge na EJA atenta que, "[...] para compreender a crítica feita, é preciso o leitor estar informado sobre essas condições de produção" (NERY, 2011 , p. 54). Logo, são as condições de produção da charge que conduzem à construção de significados e sentidos acerca da crítica presente no texto, uma vez que a crítica busca enfatizar ou chamar a atenção para aspectos de determinada situação.

De modo geral, o discurso aponta que, "[...] para ler e compreender a charge, é necessária a mobilização de conhecimentos linguísticos, sociais e cognitivos" (SOUZA, 2011 , p. 256). Os procedimentos apresentados e suas estratégias para o uso pedagógico da charge, como modalidade de leitura, mobilizam conhecimentos de ordem linguística, social e cognitiva. Em âmbito linguístico, o conhecimento aparece na identificação das articulações existentes entre a linguagem verbal e a não verbal; no campo social, aparece, sobretudo, na compreensão de um contexto social representado na charge; e em âmbito cognitivo, é relativo às percepções e às inferências que o sujeito realiza no decorrer do processo de construção de significados.

Em suma, os procedimentos empregados no discurso para compreender a charge consistem em observar as particularidades da charge, identificar a relação entre a linguagem verbal e a não verbal, localizar informações, inferir informação implícita, identificar o tema, perceber os efeitos de ironia e de humor e identificar a crítica. Tais procedimentos são um parâmetro para se ler a charge, compreendê-la e interpretá-la. Contudo, convém lembrar que utilizar a charge como modalidade de leitura não aparece de maneira unívoca, mas a partir de parâmetros que sugerem aspectos norteadores. Outros procedimentos podem ser constatados nos desdobramentos discursivos em sua contínua circulação e dispersão. Mas, no percurso analítico-descritivo realizado, o trabalho pedagógico é apresentado sob uma perspectiva ampla de busca e construção de conhecimentos. 


\section{Possibilidades e contribuições do uso da charge no cenário pedagógico}

No decorrer do discurso, identifica-se uma variedade de possibilidades e contribuições quanto ao uso pedagógico da charge como modalidade de leitura, uma vez que o processo de ler o texto chárgico aparece através de várias maneiras de fazer. Uma dessas possibilidades é a motivação. $\bigcirc$ uso pedagógico da charge se apresenta, nos escritos de Souza (2000, p. 18), "como forma de motivação", em outras palavras, "[.... ] como condição necessária para motivar seus alunos, atrair sua atenção e despertar sua curiosidade e seu interesse" (SOUZA, 2004, p. 180). O signo motivar se articula com signos que enfocam 'atrair a atenção', 'despertar curiosidade e interesse', que são os objetivos do professor para se aproximar dos alunos e incentivá-los a participar das aulas. Assim, a charge é concebida como um artefato estratégico para viabilizar essa motivação nos alunos e estimulá-los a participar do seu processo pedagógico em articulação com a própria realidade.

Além de ser demonstrada como possibilidade de provocar, atrair e despertar a atenção, a curiosidade e o interesse, pode motivar ao diálogo. Souza (2004, p. 181) refere que a charge aparece "[...] como motivação

50 com o objetivo de estabelecer o diálogo em sala de aula". O signo diálogo se destaca no discurso como um dos objetivos dessa motivação por meio do uso da charge. O diálogo viabiliza a participação do aluno e legitima sua inserção no processo pedagógico como sujeito construtor e posiciona-o no centro do processo. Em um discurso que apresenta o aluno como construtor de seu processo de aprendizagem, o diálogo existe e se constitui como uma regularidade.

discurso traz a charge como uma forma de promover uma "[...] interação do aluno com a realidade" (SOUZA, 2000, p. 18), um artefato capaz de "[...] buscar analogias com suas próprias experiências existenciais e sociais" (SOUZA, 2000, p. 58). Nesse recorte, a charge é apresentada como um meio que possibilita uma conexão entre a realidade do aluno e a realidade representada. Nesse sentido, texto chárgico é apontado como uma espécie de ponte que motiva o aluno a buscar conexões na sala de aula por meio de suas experiências, numa relação analógica nas representações de fatos e sujeitos sociais.

A charge também viabiliza "[...] compreender o contexto social e histórico e como condição de uma re-elaboração textual" (SOUZA, 2000, p. 56). 
Seu uso possibilita o acesso e o entendimento acerca de determinado espaço e tempo, uma vez que a charge é uma representação, constitui-se a partir de certa realidade e apresenta aspectos que conectam o leitor a esse dado contexto. Além disso, possibilita um processo de reconstrução ao longo da leitura, viabilizando uma reelaboração textual. A charge desperta "a capacidade de argumentação" (SOUZA, 2004, p. 235). Nesse cenário, o aluno apresenta argumentos a partir das questões que emergem do texto chárgico, concordando com o universo representado ou se contrapondo a ele. Ademais, conduz "o leitor a emitir uma opinião" (SOUZA, 2000, p. 132), o que contribui para que o aluno se posicione e tenha voz.

discurso aponta uma possibilidade de operar com a charge como um "[...] espaço de acesso do cotidiano instaurando um conhecimento que possibilite uma leitura crítica da realidade" (SOUZA, 2000, p. 18). Além de acessar o cotidiano via texto chárgico, os escritos assinalam a possibilidade de se aproximar da realidade, fomentando a criticidade dos alunos no trabalho pedagógico.

Como uma modalidade de leitura, a charge "[...] pode ser usada pelo professor para auxiliar o aluno no processo de apropriação de informações políticas e sociais" (SOUZA, 2000, p. 123). $\bigcirc$ uso desse gênero textual é atrelado ao âmbito político, e não, ao partidário, e ao ser utilizado pedagogicamente, aborda as facetas políticas da sociedade, de modo crítico e reflexivo, como um processo de (re)construção do sujeito.

Por meio desse gênero textual, pode-se, "[...] ainda, trabalhar a identidade, identificada no processo de compreensão mediado pela representação iconográfica" (SOUZA, 2000, p. 99). Os aspectos identitários também se confirmam nos seguintes escritos de Nery (2011):

[...] os discursos veiculados nas charges apresentam uma multiplicidade de vozes, que contribuem enormemente para o processo de produção de sentidos e para a construção de identidades. Dessa forma, busca observar as imagens construídas pelos alunos dos personagens apresentados nas charges (NERY, 201 1, p. 66).

Como um artefato visual, a charge viabiliza uma relação com os processos identitários por meio das múltiplas vozes existentes nela, que são identificadas pela presença de personagens em sua constituição gráfica. Assim, trabalha e problematiza as particularidades individuais e coletivas a 
partir das imagens que os alunos constroem com base nas características desses personagens e nas posições de sujeitos ocupadas na representação.

Na abordagem acerca das relações identitárias como possibilidade no discurso sobre o uso pedagógico da charge na EJA, é preciso atentar para o fato de que a identidade não é fixa, mas constantemente transformada. Ao reduzir a identidade, cria-se um simulacro que se manifesta em imagens estereotipadas que interferem diretamente na forma como somos vistos e vemos o outro (NERY, 2011 ).

Em meio ao conjunto de coisas escritas, identificam-se algumas contribuições do uso pedagógico da charge para os alunos, a saber: a conexão com a realidade, a reflexão, a problematização, a compreensão, a interpretação, o diálogo, a recorrência à memória, o desenvolvimento da capacidade de argumentar e o aguçamento da criticidade. Dessa forma, o cenário pedagógico se compreende como um lugar de construção de significados, onde o aluno elabora e reelabora o conhecimento de maneira autônoma, porquanto sua posição é de sujeito construtor.

\section{Considerações finais}

Em seus desdobramentos, este artigo trouxe uma síntese do terreno discursivo sobre o uso pedagógico da charge na EJA. Como já referido, o estudo visou entender as particularidades da charge e, mais precisamente, compreender sua conexão, no âmbito pedagógico, no que diz respeito ao seu uso na educação de jovens e adultos. Dessa forma, o uso da charge é esclarecido em suas articulações discursivas no que tange ao trabalho pedagógico, considerando-se tanto os aspectos que a constituem como artefato visual particular, ao longo da leitura, quanto as demandas para o processo de formação dos sujeitos jovens e adultos, principalmente, em relação à leitura numa perspectiva crítica.

Sob a ordem do discurso pedagógico, a charge é concebida como modalidade de leitura em seu uso pedagógico na EJA. Nesse cenário, identificaram-se sujeitos específicos que estão presentes em tal modalidade, suscitando determinada realidade no âmbito do gênero, do trabalho, das dificuldades e das oportunidades. No processo de leitura da charge, há uma regularidade triádica na relação entre o leitor, o texto e a realidade e uma série 
de procedimentos, possibilidades e contribuições que orientam e especificam esse uso pedagógico, mas que também não se reduzem a elas mesmas.

Diante do exposto, o estudo aponta que se devem fazer outras pesquisas com base nesses achados e elencar novas questões, na perspectiva de construir um novo conhecimento e um novo objeto de pesquisa. No âmbito da cultura visual, em associação com o domínio pedagógico, há muitas possibilidades para pesquisas futuras e contribuições para a formação de sujeitos críticos, no que diz respeito às representações da realidade contemporânea. Na sucessão desses estudos, repousa a busca por respostas que ressignifiquem e reconstruam a escola e suas práticas quanto às demandas e aos problemas que permeiam a contemporaneidade.

Finaliza-se com algumas questões e considerações que problematizam a temática abordada no âmbito da pesquisa em educação, ao mesmo tempo que são apresentadas algumas perspectivas para aprofundamentos e pesquisas futuras: Qual o discurso visual chárgico nos materiais didático-pedagógicos, como livros e instrumentos de avaliação? Como a charge pode ser um instrumento pedagógico empregado para potencializar a criticidade e estimular a participação do educando no processo de aprendizagem, viabilizando sua voz e vez no decorrer do trabalho pedagógico, considerando as problemáticas inerentes às relações intersubjetivas no contexto escolar (professor-aluno e aluno-aluno) e às dificuldades de aprendizagem? Como a charge se articula e contribui para o processo identitário no cenário educacional? Considerando essas questões, é importante também que se atente para o discurso político, que é inerente à charge, e ao seu uso pedagógico como uma forma de fomentar a posição dos sujeitos do processo pedagógico como cidadãos, atores sociais, participantes da história e sujeitos transformadores.

\section{Notas}

1 Sobre a sistematização desses procedimentos da AAD, ler ALCÂNTARA, Marcos; CARLOS, Erenildo. Análise Arqueológica do Discurso: uma alternativa de investigação na Educação de Jovens e Adultos (EJA).Disponível em: <http://www.anchieta.br/unianchieta/revistas/interseccoes/pdf/ Interseccoes_Ano_6_Numero_3.pdf>.

2 Angelo Agostini (1843-1910) foi um desenhista e pintor italiano que se destacou como artista gráfico com trabalhos de forte teor político e crítico, na segunda metade do Século XIX, no Brasil. Foi um dos criadores das histórias em quadrinhos no Brasil e editor e ativista político (PIRES, 2010). 


\section{Referencias}

AGOSTINHO, Aucione. A charge. 1993. 330f. Tese (Doutorado em Artes) - Programa de Pós-graduação em Artes, Universidade de São Paulo, São Paulo, 1993.

ALBUQUERQUE, Diego Luiz; OlIVEIRA, Thiago. A anatomia da charge numa perspectiva de revolução sócio-histórica. SIMPÓSIO HIPERTEXTO E TECNOLOGIAS NA EDUCAÇÃO, 2; 2008. Recife. Anais... Recife: Universidade Federal de Pernambuco. 2008.

ALCÂNTARA, Marcos; CARLOS, Erenildo. Análise Arqueológica do Discurso: uma alternativa de investigação na Educação de Jovens e Adultos (EJA). Intersecções, Jundiaí, v. 6, n. 3, p. 59-75, nov. 2013. Disponível em: http://www.anchieta.br/unianchieta/ revistas/ interseccoes/pdf/Interseccoes_Ano_6_Numero_3.pdf. Acesso em: 15 jan. 2013.

CERTEAU, Michel. A invenção do cotidiano: artes e fazer. Petrópolis: Vozes, 1994.

DAGOSTIM, Cristiane Gonçalves. A charge: funcionamento e efeitos de sentido em atividades escolares: leitura, pesquisa e produção textual. 2009. 114 f. Dissertação Mestrado em Ciências da Linguagem) - Programa de Pós-Graduação em Ciências da Linguagem, Universidade do Sul de Santa Catarina, Tubarão, 2009.

54 FOUCAULT, Michel. A arqueologia do saber. Tradução Luiz Felipe Baeta Neves. 8. ed. Rio de Janeiro: Forense Universitária, 2012.

LESSA, David. $\bigcirc$ gênero textual charge e sua aplicabilidade em sala de aula. Travessias, Sergipe, v. 1, n. 1, p. 1-17, set. 2013. Disponível em: e-revista.unioeste.br/index.php/ travessias/article/download/2803/2203. Acesso em: 15 jan. 2013.

MACÊDO, José Emerson; SOUZA, Maria Lindaci. A charge no ensino de história. In: ENCONTRO ESTADUAL DE HISTÓRIA, 13; 2007, Guarabira. Anais... Guarabira: Universidade Estadual da Paraíba, 2007. Disponível em: http://www.anpuhpb.org/anais_ xiii_eeph/textos/ST. Acesso em: 15 abr. 2013.

MAGGIONI, Fabiano. A charge jornalística: estratégias de imagem em enunciações de humor icônico. 2011 . Dissertação (Mestrado em Comunicação) - Programa de PósGraduação em Comunicação, Universidade Federal de Santa Maria, Santa Maria, 2011.

MELO, Francineide. Entre o discurso e a ironia: "o pintar o sete e desenhar os ouros" no discurso humorístico. 2004. Dissertação (Mestrado em Letras) - Programa de Pós-Graduação em Letras, UFPB, João Pessoa, 2004. 
MOUCO, Maria Aparecida; GREGÓRIO, Maria Regina. Leitura, análise e interpretação de charges com fundamentos na teoria semiótica. Londrina: Dia a dia Educação, 2007. Disponível em: http://www.diaadiaeducacao.pr.gov.br. Acesso em: 15 abr. 2013.

NERY, Luciana Fernandes. A situação é que faz o leitor: uma análise das relações entre os sujeitos de ensino da EJA na leitura de charges. 2011 . 150f. Dissertação (Mestrado em Linguagem e Ensino) - Programa de Pós-Graduação em Linguagem e Ensino, Universidade Federal de Campina Grande, Campina Grande, 2011.

PIRES, Maria Conceição. Centenário do traço: o humor político de Ângelo Agostini na Revista llustrada (1876-1888). Rio de Janeiro, 2010. Disponível em: http://www.bn.br/ portal/arquivos/pdf/Maria_Conceicao.pdf Acesso em: 15 abr. 2013.

SILVA, Carla Letuza. O trabalho com charges na sala de aula. Porto Alegre, 2004. Disponível em: https://pt.scribd.com/document/338696203/o-Trabalho-Com-Charges-Na-Sala-de-Aula Acesso em: 20 de fev. 2013.

SILVA, Ivam. Humor gráfico: o sorriso pensante e a formação do leitor. 2008. $131 \mathrm{f}$. Dissertação (Mestrado em Educação) - Programa de Pós-Graduação em Educação, Universidade Federal do Rio Grande do Norte, Natal, 2008.

SOUZA, Cláudia Mara. Leitura de charge: uma experiência, um desafio. Revista Via Litterae, Anápolis, v. 3, n. 2, p. 247-259, jul./dez. 2011 . Disponível em: www.unucseh. veg.br/vialitterae Acesso em: 15 ago. 2013.

SOUZA, Maria Lindaci. Desvelando máscaras: a charge como modalidade de leitura do cotidiano. 2000. 238f. Dissertação (Mestrado em Educação) - Programa de Pós-Graduação em Educação, Universidade Federal do Rio Grande do Norte, Natal, 2000.

Iconografia humorística no ensino de história: modalidades de uso na sala de aula. 2004. 555f. Tese (Doutorado em Educação) - Programa de Pós-Graduação em Educação, Universidade Federal do Rio Grande do Norte, Natal, 2004.

Ms. Raissa Regina Silva Coutinho Universidade Federal da Paraíba | João Pessoa Programa de Pós-Graduação em Educação Grupo de estudos e pesquisas em Educação de Jovens e Adultos | GEPEJA E-mail | coutinho_raissa@hotmail.com 
Prof. Dr. Erenildo João Carlos

Universidade Federal da Paraíba | João Pessoa

Programa de Pós-Graduação em Educação Líder do Grupo de estudos e pesquisas em Educação de Jovens e Adultos | GEPEJA E-mail | erenildojc@hotmail.com Blog | http://paedagogiumejc.blogspot.com.br

Recebido 31 out. 2017 Aceito 28 nov. 2017 